\title{
Análise dos parâmetros físico-químicos do esgoto tratado de Curitiba (PR) - Estação Belém
}

\author{
Analysis of physical and chemical parameters of sewage treated in the city of \\ Curitiba (Brazil) - Belem plant
}

\author{
Audrey Elis Michalake ${ }^{1}$, Cristiane Rosa da Silva ${ }^{2}$ e Frederico Fonseca da Silva ${ }^{3}$ \\ 1,2Aluna concluinte do Curso Tecnólogo de Gestão Pública pelo IFPR - Instituto Federal do Paraná. \\ Curitiba/PR, Brasil \\ audrey_michalake@hotmail.com;crisrosa_silva@hotmail.com
}

${ }^{3}$ Engenheiro Agrônomo. Doutor em Irrigação e Meio Ambiente. Professor e Pesquisador do IFPR - Instituto

Federal do Paraná. Doutor pela UEM - Universidade Estadual de Maringá. Curitiba/PR, Brasil

frederico.silva@ifpr.edu.br

\begin{abstract}
Resumo
O crescimento populacional desordenado, aliado ao pouco avanço do saneamento básico no Brasil, tem como consequência diversos problemas estruturais como o abastecimento de água, esgotamento sanitário, manejo de resíduos sólidos entre outros que não tem sido tratado muitas vezes de maneira adequada. No Brasil a realidade sanitária está muito aquém das condições ambientais ideais. O esgoto é pouco coletado e tratado, sendo muitas vezes despejados nos corpos receptores. Por isso procuramos analisar os parâmetros físico-químicos do esgoto tratado da Estação de Tratamento de Esgoto - Belém em Curitiba para verificarmos se está de acordo com a Resolução CONAMA No 430/2011 e se o mesmo esgoto está apto a voltar ao corpo receptor. De acordo com as análises físico-químicas do esgoto tratado, pudemos verificar que as mesmas atendem a legislação vigente embora tenha apresentado IQA abaixo do recomendado no Paraná.
\end{abstract}

Palavras-chave: Saneamento básico; Esgotamento sanitário; Efluente.

\begin{abstract}
The disordered population growth, coupled with little progress sanitation in Brazil, results in many structural problems such as water supply, sanitation, solid waste management among others that have not been treated often properly. In Brazil, the health situation is far from ideal environmental conditions. The sewage is collected and treated little, often dumped into receiving canals. So we try to analyze the physical and chemical parameters of treated wastewater from sewage treatment station Belem in Curitiba (Brazil) to verify if is according to CONAMA Resolution No. 430/2011 and if treated sewage is able to get back the receiving body. According to the physicalchemical analysis of treated sewage, it could verify that they meet the current legislation although IQA presented below recommended in Paraná.
\end{abstract}

Keywords: Sanitation; Sewage water; Effluent. 


\section{Introdução}

Podemos elencar alguns motivos importantes que fazem o estudo sobre saneamento básico ser tão importante para a pesquisa, tais como, eficiência econômica, equidade social e qualidade de vida, uma vez que o mesmo envolve várias áreas como a saúde pública, meio ambiente e a economia de uma cidade. Onde, tudo isso está inserido no contexto de um planejamento urbano condizente com os propósitos da Gestão Pública.

Somando esses fatores, vários cidadãos brasileiros ainda não possuem acesso a um bem comum e de direito: água potável, sendo que a coleta de esgoto é insuficiente e o tratamento de esgoto é quase nulo (WAGNER, MOURA, 2013). Ou seja, em pleno século XXI, observase uma dupla falha: a falta de acesso à água potável; e, dos que têm, quase que a total insuficiência na coleta e tratamento do esgoto coletado.

De acordo com o Plano Nacional de Saneamento Básico (MINISTÉRIO DAS CIDADES, 2013) e em concordância com a Lei 11.445/07 (BRASIL, 2007), saneamento básico conceitua-se como o conjunto de serviços, infraestruturas e instalações de abastecimento de água, esgotamento sanitário, limpeza urbana e manejo de resíduos sólidos e drenagem de águas pluviais urbanas.

Porém, de acordo com World Health Organization (WHO, 2004), define-se saneamento como o controle de todos os fatores do meio físico do ser humano que exercem ou podem exercer efeitos nocivos sobre o bem estar físico, mental e social. Observando que nesse contexto insere-se a variável água e seus desdobramentos. Ou seja, embora as duas definições divirjam sobre o conceito podemos dizer que são medidas essenciais para garantir o desenvolvimento urbano e para melhorar a qualidade de vida e a saúde das pessoas.

Para o Instituto Trata Brasil (INSTITUTO TRATA BRASIL, 2015), uma OSCIP1 , essas medidas devem ser adotadas pelos três níveis do governo (Municipal, Estadual e Federal) e devem contemplar o abastecimento de água tratada, coleta e tratamento de esgoto, limpeza urbana, manejo de resíduos sólidos e drenagem das águas fluviais.

Ressaltamos que neste trabalho consideramos como foco do estudo apenas uma pequena parte do que se compreende por saneamento básico - a parte dos esgotos sanitários e o seu tratamento.

A pesquisa, como objetivo geral, procurou identificar se a SANEPAR ${ }^{2}$ destina corretamente o esgoto tratado aos corpos receptores de acordo com as especificações da Resolução do CONAMA ${ }^{3}$ 430/2011 (CONAMA, 2011). Contudo, em função da variável água ser fator limitante ao desenvolvimento humano, principalmente no ano em que esse estudo foi elaborado, comparamos os seus

1 OSCIP - Organização da Sociedade Civil de Interesse Público

2 SANEPAR - Companhia de Saneamento do Paraná

3 CONAMA - Conselho Nacional do Meio Ambiente parâmetros com a Classe 3 da referida Resolução, como forma de aproveitar e reutilizar esse esgoto de descarte para fins de fertirrigação.

Segundo Testezlaf (1987) a fertirrigação consiste na aplicação de fertilizantes via água de irrigação.

Para atingir o objetivo geral foram estabelecidos os seguintes objetivos específicos: Analisar os parâmetros físico-químicos $\mathrm{DBO}^{4}, \mathrm{DQO}^{5}, \mathrm{SS}^{6}, \mathrm{SST}^{7}$ e $\mathrm{pH}^{8}$ do esgoto pré e pós-tratado; e, Identificar se o esgoto tratado está em condições adequadas para voltar ao corpo receptor, apto a ser utilizado para fins de fertirrigação de área públicas (parques e jardins) ou produção de biomassa.

Justifica-se este estudo pelo fato de que sem um tratamento sanitário adequado dos resíduos, o sistema de esgotamento poderá induzir a uma deterioração do corpo receptor (SOARES et al., 2002).

\section{Fundamentação teórica}

\section{Esgotos}

A água é um recurso natural de suma importância para a sobrevivência de todas as espécies que habitam o Planeta Terra e este recurso vem sendo usado de maneira negligente e irresponsável por parte dos consumidores e dos órgãos competentes (HENNRICH, 2010).

É possível constatar isso através dos dados do UNI$\mathrm{CEF}^{9}$ e da $\mathrm{OMS}^{10}$ onde revelam que quase metade da população mundial (2,6 bilhões de pessoas) não conta com serviço de saneamento básico e que uma em cada seis pessoas (cerca de 1,1 bilhões de pessoas) ainda não possui sistema de abastecimento de água adequado $\left(\mathrm{MMA}^{11}, \mathrm{~s} / \mathrm{a}\right)$.

Até mesmo os países que possuem recursos hídricos abundantes, como o Brasil, não estão livres da ameaça de uma crise hídrica, como aconteceu neste ano de 2015, principalmente com o estado de São Paulo, que viveu a pior escassez de água dos últimos 80 anos (RIBEIRO, 2014). Por isso é tão importante à conservação dos recursos hídricos e o tratamento adequado dos resíduos, pois de acordo com Ohira (2005), pode tornar inviável o uso da água dos rios, lagos e reservatórios para o consumo e até mesmo irrigação.

O esgoto sanitário, definido pela NBR 9648 (ABNT, 1986), é o despejo líquido constituído de esgotos doméstico e industrial, água de infiltração e a contribuição pluvial parasitária. Essa mesma norma define ainda: esgoto doméstico é o despejo líquido resultante do uso da água para higiene e necessidades fisiológicas hu-

\footnotetext{
4 DBO - Demanda Bioquímica de Oxigênio

5 DQO - Demanda Química de Oxigênio

6 SS - Sólidos Sedimentáveis

7 SST - Sólidos Suspensos Totais

pH - Potencial Hidrogeniônico

9 UNICEF - Fundo das Nações Unidas para a Infância.

10 OMS - Organização Mundial da Saúde

11 MMA - Ministério do Meio Ambiente
} 
manas; esgoto industrial é o despejo líquido resultante dos processos industriais, respeitados os padrões de lançamento estabelecidos; água de infiltração é toda água proveniente do subsolo, indesejável ao sistema separador e que penetra nas canalizações; e, contribuição pluvial parasitária é a parcela do deflúvio superficial inevitavelmente absorvida pela rede de esgoto sanitário.

O grande impasse em relação às águas, atualmente no Brasil, consiste na poluição originada pelos esgotos sanitários (GRANZIERA, 2014). Durante muito tempo os poderes públicos preocuparam-se com o abastecimento de água potável à população, mas esqueceram de que o tratamento do esgoto e a qualidade da água são tão importantes quanto o fornecimento de água.

As Diretrizes Básicas para o Saneamento Básico, instituída pela Lei 11.445/2007 (BRASIL, 2007), deferiu quatro serviços: abastecimento de água; esgotamento sanitário (compreendendo a coleta e o tratamento do esgoto); limpeza urbana; e; drenagem.

De acordo ainda com Granziera (2014), observa-se que o regulamento normativo do Brasil é parcialmente suficiente para garantir a qualidade e quantidade de água limpa. Mas apenas a lei não basta. É necessário a União, os estados e os municípios trabalharem em conjunto, considerando a água como um bem de valor econômico, social e ecológico.

Através dos estudos de Libânio, Chernicharo e Nascimento (2005) comprovam-se que os estados brasileiros que investiram menos em cobertura de esgotamento obtiveram os piores indicadores sociais; enquanto aqueles estados que tiveram maior cobertura obtiveram melhores índices sociais.

\section{Estação de tratamento de esgoto}

O abastecimento de água vem evoluindo consideravelmente no Brasil, segundo o Sistema Nacional de Informações em Saneamento (SNIS, 2013), porém o crescimento da rede sanitária é lento e ineficaz.

Coleta-se pouco esgoto e trata-se menos ainda, cerca de $82,5 \%$ dos brasileiros são atendidos com abastecimento de água tratada, mas somente $48,6 \%$ da população têm acesso a coleta de esgoto e, desse, apenas 39\% é tratado (INSTITUTO TRATA BRASIL, 2011); e, muitas vezes, o que é coletado volta ao corpo receptor (rios) com muitas impurezas, consequentemente, contaminando os afluentes e, principalmente, à jusante desencadeando um processo que prejudica a saúde da população e polui o meio ambiente.

A existência de um sistema de tratamento de esgoto sanitário se faz necessário, pois melhora a qualidade de vida da população, reduz a mortalidade infantil e tem como finalidade proteger da contaminação os afluentes, preservando o meio ambiente e dirimindo problemas de ordem sanitária e doenças, como diarreia, cólera, dengue, hepatite, etc. (SANEPAR, 2010).

Para Van Haandel e Lettinga (1994) apud Fernandes
(2007), o objetivo principal do tratamento de esgoto é corrigir as suas características indesejáveis, de tal maneira que o seu uso ou a sua disposição final possa ocorrer de acordo com as regras e critérios definidos pelas autoridades regulamentadoras.

Existem duas modalidades de coleta de esgoto, uma é o sistema unitário, onde ambos os esgotos: domiciliares, industriais e águas das chuvas (pluviais) são coletadas pelo mesmo sistema coletor; e, o sistema separador, onde são coletadas as águas residuárias domiciliares e industriais e as águas pluviais em outro sistema coletor cada um (MMA, 2009).

Desta forma, a água originária das construções residenciais, industriais e deflúvios são coletados e encaminhados por uma rede canalizada até as ETEs ${ }^{12}$, onde é desenvolvido o tratamento da mesma, para seu depósito final nos mananciais do município.

Através de uma ETE é realizado o tratamento do esgoto sanitário, com a separação da parte sólida da parte líquida, tratando ambas, com vistas à redução da poluição. Para CASAN ${ }^{13}$ (CASAN, S.A.), a ETE é a:

Unidade operacional do sistema de esgotamento sanitário que através de processos físicos, químicos ou biológicos removem as cargas poluentes do esgoto, devolvendo ao ambiente o produto final, efluente tratado, em conformidade com os padrões exigidos pela legislação ambiental.

A ETE tem a função de remover a carga orgânica (basicamente constituída de gorduras, carboidratos e proteínas) e tratar o esgoto que vêm das residências e demais ambientes das cidades e devolvê-lo em forma de água tratada. Desenvolvendo um ciclo sustentável de reaproveitamento e possível reuso da água. O esgoto captado é submetido, conforme o grau de pureza que se deseja atingir, a três níveis de tratamento, e estes, subdivididos a uma série de etapas até que esteja em condições de reuso (SANTOS e MANCUSO, 2003).

Para a SABESP (MMA, 2009) os níveis de tratamento de esgoto podem ser divididos em: tratamento Preliminar: remoção de sólidos grosseiros e areia; tratamento Primário: remoção de sólidos em suspensão sedimentáveis e de sólidos flutuantes; e, tratamento Secundário: remoção de matéria orgânica dissolvida e matéria orgânica em suspensão.

Os sistemas de tratamento podem ser aeróbios ou anaeróbios. Para o Ministério do Meio Ambiente (MMA, 2009):

A escolha do Processo de Tratamento de Esgoto baseia-se principalmente no nível de eficiência desejado (consequência da qualidade do efluente final, compatível com a necessidade do corpo receptor), na área disponível para sua implantação, no custo e na complexidade de implantação e operação de cada processo, nas condicionantes ambientais

12 ETE - Estação de Tratamento de Esgoto

13 CASAN - Companhia Catarinense de Águas e Saneamento 
relativas à locação da unidade, na produção e disposição de lodos e na dependência de insumos externos.

A ETE Belém, situada na bacia do Alto Iguaçu, operada pela SANEPAR, é uma das maiores estações de tratamento de esgoto da grande Curitiba e serve também aos municípios de Pinhais e São José dos Pinhais (SANEPAR, 2010).

Essa estação atua com um sistema de aeração prolongada, por lodo ativado, chamado sistema aeróbio, tratando em média de 1.1001/s de esgoto.

O sistema aeróbio corresponde ao sistema analisado neste trabalho, e é um sistema que utiliza a aeração prolongada em fluxo orbital - sistema carrossel, que encerra um efluente com alta qualidade, superior a 95\% no resultado final (SANEPAR, 2010).

Esse tratamento aeróbico, segundo Sperling (1996a), tem por objetivo primeiramente remover parte da matéria orgânica, também sólidos sedimentares, utilizando-se de mecanismos físicos para remoção dos poluentes; e, no tratamento secundário, que se inicia logo após esse processo, é feita a remoção da matéria orgânica e, casualmente, nutriente (nitrogênio e fósforo), desenvolvida através de processos biológicos.

Passando nessa fase para os tanques de aeração, onde o oxigênio é introduzido na massa líquida. Isso é realizado porque os microrganismos aeróbios necessitam de ar para absorverem e degradarem grande quantia de matéria. A este processo dá-se o nome de lodo ativado, um dos mais usados no tratamento de águas residuárias, devido a sua grande eficiência. Este processo, quando bem arquitetado e exemplarmente executado terá eficiência próxima de $98 \%$, no que corresponde à extração de DBO solúvel (NUVOLARI, 2011).

Quando o processo chega aos decantadores, o lodo é sedimentado por gravidade e a água, já tratada, é retirada superficialmente através de uma calha que segue por um canal e é descartada no corpo receptor (SANEPAR, 2010).

Esse líquido do descarte deve estar livre de substâncias tóxicas nocivas ao meio ambiente e em conformidade com a Resolução 357/2005 do CONAMA (CONAMA, 2005), especificado para o seu uso e fim.

Algumas vezes a água, que é o resultado desse processo de tratamento sanitário, e é devolvida ao rio, está mais pura que a água do próprio rio. O lodo resultante, parte é devolvida ao tanque de aeração e outra parte segue para o adensador. Ao passar para o adensador o lodo é comprimido e vai ao leito de secagem (SANEPAR, 2010).

\section{Sistema Aeróbio}

Conforme processo descrito pela SANEPAR (SANEPAR, 2010), o tratamento do esgoto coletado e tratado pela ETE Belém, funciona conforme Figura 1, que define as fases do tratamento aeróbio da seguinte maneira: (a) $\mathrm{O}$ esgoto é conduzido, dos imóveis e indústrias, pela Rede Coletora; (b) Passa pela Estação Elevatória; (c) Chega então, ao Gradeamento Mecânico Desarenador, onde se faz a peneiração dos sólidos e areia; (d) Nessa fase recebe o oxigênio para alimentar os micro-organismos; (e) Quando o processo chega aos Decantadores, o lodo é sedimentado por gravidade e água; e, (f) Aqui, o lodo resultante do tratamento passa para a Secagem Mecânica, onde é comprimido e depois do prazo de secagem é enviado ao local de reaproveitamento do mesmo.

Os efluentes gerados nas ETEs podem ser reutilizados para descarga e diluição nos rios e lagoas ou reutilizados em solo agrícola e pisciculturas (BASTOS et al., 2005)

A tecnologia avança a cada dia em processos de reu-

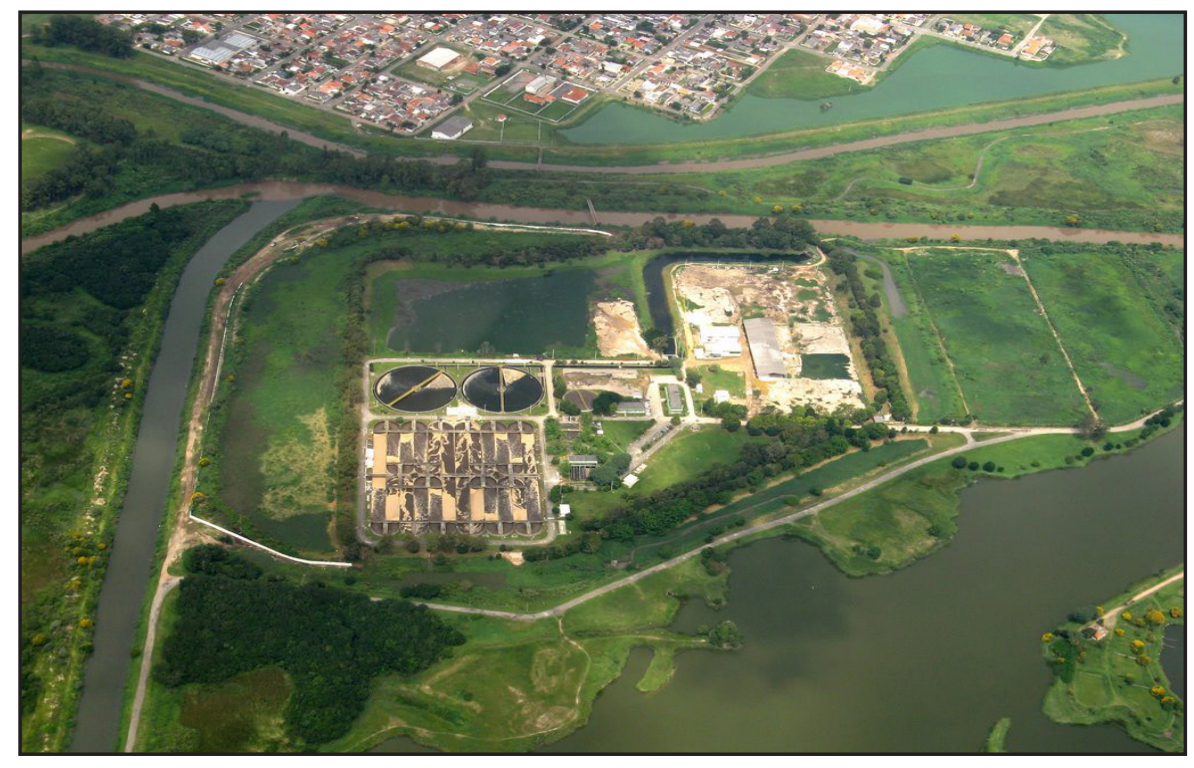

Figura 1 - Estação de Tratamento de Esgoto - Unidade Belém em Curitiba (PR)

Fonte: SANEPAR (2010) 
Tabela 1. Dados da ETE Belém

\begin{tabular}{|ll|}
\hline \hline ETEs & Dados de projeto \\
\hline Belém & \\
População Atendida & 500.000 habitantes \\
Vazão Média & $870,00 \mathrm{~L} / \mathrm{s}$ \\
Tempo de Detenção & 28 horas/reator \\
Volume do Reator & $84.000 \mathrm{~m}^{3}$ \\
Remoção da Matéria Orgânica & $97 \%$ \\
Bacia & Belém \\
Corpo Receptor & Rio Iguaçu \\
Inauguração & Março 1979 \\
Bairro & Boqueirăo - Curitiba \\
Localização & Parque Iguaçu s/n \\
Atendimento & Parte de Săo José dos Pinhais e parte de Curitiba \\
Tratamento & Tipo Aeróbio, composta de dois tanques de Aeração do tipo \\
& Lodo Ativado \\
Georreferenciamento: & X: 679641 e Y: 7176968 (coordenadas UTM) \\
Entrada de Esgoto & X: 679616 e Y: 7176529 (coordenadas UTM) \\
Saída de Esgoto & \\
\hline \hline
\end{tabular}

Fonte: SANEPAR (2010)

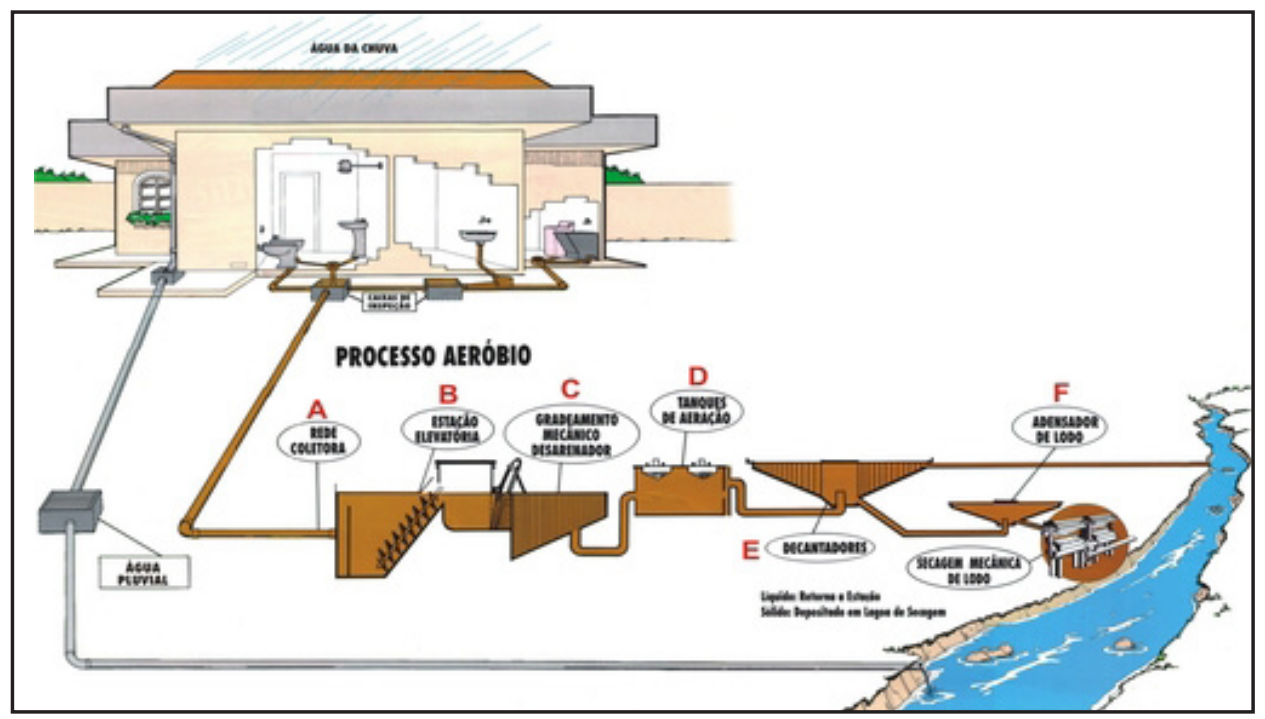

Figura 2 - Processo de Tratamento de Esgoto

Fonte: SANEPAR (2010)

tilização de parte do que é retirado do esgoto doméstico. Variadas são as formas de reuso, não só da água residuária, mas também da areia e do lodo resultante desses tratamentos, porém é de suma importância, observar os princípios básicos para o reuso desses materiais, tais como: a preservação da saúde dos usuários, o atendimento às leis que regulamentam a qualidade e a proteção ao meio ambiente (HESPANHOL, 2002).

\section{Análises físico-químicas}

Segundo Portaria no 2.914, de 11 de dezembro de 2011 (MINISTÉRIO DA SAÚDE, 2011), para que a água seja potável e adequada ao consumo humano, deve apresentar características microbiológicas, físicas, químicas e radioativas que atendam a um padrão de potabilidade estabelecido.

Isso leva à necessidade de tratamento prévio da água principalmente para os consumos domésticos e industriais, que possuem requisitos de qualidade mais exigentes, conforme sugere USEPA (2004) apud FRANCO (2010).

A realização das análises físicas e químicas, durante as etapas do tratamento do esgoto, possibilita o acompanhamento da eficiência do mesmo e determina a necessidade, ou não, de implementação de medidas preventivas e/ou corretivas (SAMAE, s/a).

Além disso, o controle serve para caracterizar e monitorar o efluente tratado. As análises estudadas por este artigo foram: PH, SST, SS, DQO e DBO, descritos de acordo com a Tabela 2. 
Tabela 2 - Principais parâmetros físico-químicos do esgoto

\begin{tabular}{c|c}
\hline Parâmetros & Descrição \\
\hline $\mathrm{pH}$ & A medida do pH indica a acidez ou basicidade de uma solução. \\
\hline DQO & $\begin{array}{r}\text { Representa a quantidade de oxigênio requerida para estabilizar, quimicamente, a } \\
\text { matéria orgânica carbonácea. }\end{array}$ \\
\hline DBO & $\begin{array}{r}\text { Representa o consumo total de oxigênio, ao final de vários dias, requerida pelos } \\
\text { micro-organismos para a estabilização bioquímica da matéria orgânica. }\end{array}$ \\
\hline SST & Fração de sólidos inorgânicos e orgânicos que não são filtráveis (não dissolvidos) \\
Fonte: Adaptação de Spring & $\begin{array}{c}\text { Fração dos sólidos orgânicos e inorgânicos que sedimenta em uma hora no cone } \\
\text { Imhoff }\end{array}$ \\
\hline
\end{tabular}

\section{Materiais e métodos}

O presente estudo foi realizado através dos dados fornecidos pela Sanepar - Estação de Tratamento de Esgoto, Unidade Belém, localizado na cidade de Curitiba (PR). A escolha da ETE Belém ocorreu devido ao fato da SANEPAR nos passar somente os dados desta ETE para análise.

Através destes dados, realizamos uma pesquisa bibliográfica e descritiva, onde pudemos comparar os dados da ETE - Belém, num período de 10 anos (2003 - 2013).

Com base nos valores médios apresentados pela Sanepar, comparamos com a Resolução 430/2011, do CONAMA (CONAMA, 2011) utilizando, para isso, a Classe 3 da Resolução 357/2005 (CONAMA, 2005), que trata das especificações mínimas para fins de fertirrigação, conforme detalhado no Tabela 3.

As descrições e análises críticas dos parâmetros seguiram com base nas recomendações do CONAMA e do Ministério da Saúde e alguns autores da área.

\section{Resultados e discussões}

A Resolução № 430, de 13 de maio de 2011 (CONAMA, 2011), que dispõe sobre os parâmetros, condições, padrões e diretrizes para gestão do lançamento de efluentes em corpos de águas receptores, alterou parcialmente e complementou a Resolução № 357, de 17 de março de 2005, do CONAMA, a qual discorre sobre a classificação e diretrizes ambientais para o enquadramento dos corpos de águas superficiais, bem como estabelece as condições e padrões de lançamento de efluentes.

Em um breve histórico, observa-se que o Brasil apresenta certa morosidade no que se refere a critérios de parâmetros de monitoramento da sua água, bem como dos valores máximos permitidos para os seus usos e reusos. Por exemplo, a Resolução № 020/85 do CONAMA perdurou por 20 anos, até o ano de 2005, para que esses valores e parâmetros fossem revisados com a edição da Resolução № 357 .

Muito embora a Resolução № 357/05 tenha levado

Tabela 3 - Descrição e uso da água para a classe 3, de acordo com Conama (2011)

\begin{tabular}{l|c}
\hline Classe & \begin{tabular}{c} 
Destinação para uso \\
\hline \multirow{4}{*}{3}
\end{tabular} \\
\cline { 2 - 2 } & $\begin{array}{c}\text { Abastecimento para consumo humano, após tratamento convencional ou } \\
\text { avançado; }\end{array}$ \\
\cline { 2 - 2 } & Irrigação de culturas arbóreas, cerealíferas e forrageiras; \\
\cline { 2 - 2 } & Pesca amadora; \\
\cline { 2 - 2 } & Recreação de contato secundário; \\
\hline
\end{tabular}

Tabela 4 - Parâmetros máximos estabelecidos pela Resolução 430/2011

\begin{tabular}{c|c}
\hline PARÂMETROS & Valores máximos - Resolução 430/2011 CONAMA \\
\hline DBO $(\mathrm{mg} / \mathrm{l})$ & até $10 \mathrm{mg} / \mathrm{L} \mathrm{O} 2\left(5\right.$ dias a $\left.20^{\circ} \mathrm{C}\right)$ \\
\hline DQO $(\mathrm{mg} / \mathrm{l})$ & remoção de $20 \%$, após desarenação \\
\hline S. S. T. $(\mathrm{mg} / \mathrm{l})$ & até $1 \mathrm{~mL} / \mathrm{L}$ em teste de 1 hora em cone Inmhoff \\
\hline S. S. $(\mathrm{mg} / \mathrm{l})$ & entre 5 e 9 \\
\hline pH &
\end{tabular}


Tabela 5 - Comparação dos parâmetros físico-químicos de 2003 e 2013

\begin{tabular}{c|c|c|c|c|c|c}
\hline \multicolumn{3}{c|}{ ETE Belém 2003 } & & \multicolumn{3}{c}{ ETE Belém 2013 } \\
\hline Parâmetros & Afluente & Efluente & & Parâmetros & Afluente & Efluente \\
\hline DBO (mg/l) & 313,75 & 32,31 & & DBO $(\mathrm{mg} / \mathrm{l})$ & 297,90 & 21,00 \\
\hline DQO $(\mathrm{mg} / \mathrm{l})$ & 594,06 & 89,88 & & DQO $(\mathrm{mg} / \mathrm{l})$ & 524,00 & 57,50 \\
\hline S.S $(\mathrm{mg} / \mathrm{l})$ & 313,77 & 53,12 & & S.S $(\mathrm{mg} / \mathrm{l})$ & 233,60 & 27,30 \\
\hline S.S.T. $(\mathrm{mg} / \mathrm{l})$ & 15,86 & 7,32 & & S.S.T. $(\mathrm{mg} / \mathrm{l})$ & 6,20 & 0,30 \\
\hline $\mathrm{pH}$ & 6,90 & 6,90 & & $\mathrm{pH}$ & 7,20 & 7,20 \\
\hline
\end{tabular}

Fonte: Tabela adaptada de Schilling et al. (2013) e Trentin (2005)

'apenas' seis anos para uma nova revisão (Resolução № 430/11), a mesma não contempla parâmetros, por exemplo, de critérios para vírus das águas urbanas ou não apresenta padrões máximos para a variável DQO.

Para os parâmetros estudados, especificados na Classe 3, os valores máximos são apresentados no Tabela 4.

$\left(^{*}\right)$ A Resolução 430/2011 CONAMA não estabelece padrões máximos para DQO.

Porém, é importante ressaltar, que o CONAMA no 357/05 permite que determinados parâmetros sejam definidos a critério do órgão ambiental competente de cada Estado, como é o caso do lançamento de efluentes tratados pelas ETEs.

No Paraná, esses parâmetros são fixados pelo IAP ${ }^{14}$ e estabelecidos na licença de operação. Exemplos de alguns parâmetros que são fixados: $60 \mathrm{mg} / \mathrm{L}$ para DBO; $150 \mathrm{mg} / \mathrm{L}$ para DQO; $50 \mathrm{mg} / \mathrm{L}$ para SS como limite máximo (Trentin, 2005).

Em função disso, os efluentes tratados nas ETEs podem apresentar concentração maior em relação ao permitido pelo CONAMA para irrigação de culturas agrícolas.

Os resultados médios dos parâmetros físico-químicos nesse estudo comparados em um intervalo de 10 anos, pela Sanepar (Tabela 5).

\section{Análise da DBO}

Entende-se DBO como a quantidade de oxigênio necessária para estabilizar bioquimicamente a matéria orgânica contida na água residuária. De sorte que, quanto mais elevado for o seu valor, maior necessidade de oxigênio a ser requerido para se estabilizar os compostos orgânicos por processos bioquímicos.

Com base nos valores apresentados no Tabela 5, observa-se que a carga do esgoto bruto (Afluente) coletada por essa ETE teve uma redução da ordem de $5,0 \%$ considerando o intervalo de tempo de dez anos, onde passou a lançar, seletivamente nos esgotos, cargas

14 IAP - Instituto Ambiental do Paraná orgânicas menores.

Para o efluente lançado no corpo receptor, esse valor também foi reduzido em $35 \%$, passando de 32,21 para $21 \mathrm{mg} / \mathrm{l}$, nesse caso, pelo fato de aplicar técnicas mais eficientes na injeção de oxigênio no sistema de tratamento. E, as suas reduções temporais para do esgoto bruto para o tratado, nos anos estudados, foram da ordem de 89,70 e $92,95 \%$; e, nominalmente, para o mesmo período estudado, de 281,44 e 276,90 mg/l.

O CONAMA (2011) refere-se que a DBO possua no máximo $120 \mathrm{mg} / \mathrm{l}$ enquanto o IAP fixa o valor em até $60 \mathrm{mg} / \mathrm{l}$. Assim, diante dos parâmetros propostos pelas duas instituições ambientais, uma federal e a outra estadual, podemos dizer que o DBO do efluente, tanto em 2003, quanto em 2013, atende o valor exigido pelos órgãos reguladores para descarte.

\section{Análise da DQO}

A definição de DQO pode ser estabelecida como a medida da quantidade de oxidante químico necessário para oxidar a matéria orgânica de uma amostra. Também é expressa em miligramas de oxigênio por litro do efluente, de acordo com Standard Methods (APHA, 1998).

A resolução 357/05 do CONAMA (Brasil, 2005) não traz referência ao parâmetro de DQO na classificação dos corpos d'água e nos padrões de lançamento de efluentes líquidos, estabelecendo parâmetros apenas a Demanda Bioquímica de Oxigênio (DBO).

A Resolução 430/11 do CONAMA (BRASIL, 2011), que complementa e altera a 357/05, continua sem indicar a DQO nos parâmetros de lançamento de efluentes. Porém, algumas legislações ambientais estaduais estabelecem limites máximos para este parâmetro no IQA ${ }^{15}$ para reservatórios ou para empreendimentos industriais, como no Paraná (IAP, 2004) que estabelece para DQO $50 \mathrm{mg} / \mathrm{L}$ enquanto que para SABESP (2009) o parâmetro máximo estabelecido é de $180 \mathrm{mg} / \mathrm{L}$.

Dos valores coletados neste intervalo de 10 anos, obser15 IQA - Índice de Qualidade da Água 
va-se que a DQO reduziu no seu afluente bruto algo em torno de $11,79 \%$, pelas mesmas razões apresentadas para a DBO; enquanto o efluente tratado obteve uma redução de $36,02 \%$, o que traduz em uma melhora em relação ao grau de poluição do esgoto tratado.

Contudo, na falta de regras claras e valores máximos expressos, observa-se que as resoluções são omissas para descarte do esgoto tratado, mas impeditiva para o IQA Paraná, uma vez que o esgoto tratado apresenta valor de 57,50 mg/l contra o máximo permitido de 50,00 mg/l, ou seja, a qualidade da água está abaixo do parâmetro estabelecido pelo IQA no Paraná.

\section{Análise dos sólidos totais e sólidos sedimentáveis}

Entende-se por Sólidos Totais como toda a matéria contida nas águas residuárias, que não seja água podendo apresentar-se na forma de substâncias sedimentadas ou em suspensão. A determinação dos sólidos suspensos fornece uma estimativa da matéria orgânica presente no resíduo.

Sólidos Sedimentáveis são a porção sólida que sedimenta após o processo de secagem ou evaporação (MELO et al., s/a)

Para Benn e McAuliffe (1981), grande parte dos sólidos suspensos, que são todas as partículas que ficam em suspensão e podem ser retidas em uma membrana de porosidade igual a 1 mícron $^{16}$, são formados de microorganismos vivos ou mortos que advêm das fezes ou de outros poluentes e podem multiplicar-se nos esgotos numa reação com outros organismos.

Estes dois parâmetros, segundo Trentin e Bostelman (2010), se não estiverem devidamente controlados podem causar graves danos, especialmente à vida aquática, aumentando a sedimentação no leito dos rios, destruindo as fontes de alimento, diminuindo a incidência da luz, retendo resíduos orgânicos no fundo dos mesmos, desencadeando uma decomposição anaeróbia, podendo dizimar toda uma espécie.

Confrontando as informações contidas nos Tabelas $4 \mathrm{e}$ 5, verifica-se que esses parâmetros tiveram uma melhora significativa no intervalo de dez anos (2003 - 2013) e estão de acordo com a legislação pertinente.

Para sólidos em suspensão o CONAMA (2011) especifica remoção de $20 \%$ após a desarenação. A variação do parâmetro em 10 anos obteve a redução de 48,60\% do efluente.

Em relação aos sólidos sedimentáveis, o CONAMA (2011) refere-se apenas para que estejam virtualmente ausentes, a variação percentual desse parâmetro consta $95,90 \%$ do efluente.

\section{Análise do $\mathrm{pH}$}

Entende-se por $\mathrm{pH}$, a medida que indica a acidez ou basicidade de uma solução. A escala universal do pH é

16 Um mícron equivale à milésima parte do milímetro, sendo portanto um milionésimo do metro. de 0 a 14. Assim, soluções com pH abaixo de 7 são ditas ácidas e soluções com pH acima de 7 são ditas básicas.

Os valores de $\mathrm{pH}$ para os esgotos em processo de tratamento podem variar entre 5 a 9 . A lei brasileira ainda mantem uma grande amplitude nos valores de destarte do seu efluente 'aceitando' de ácido fraco a básico fraco, como por exemplo, é o $\mathrm{pH}$ da soda cáustica.

O controle do $\mathrm{pH}$ no tratamento do esgoto é um dos fatores mais importantes a ser mantido para se obter uma boa eficiência do processo. $\mathrm{O}$ pH geralmente é medido em equipamentos específicos para este fim, através do método potenciométrico (SAMAE, s/a)

Em relação ao pH, o CONAMA (2011) estipula uma variação de 5 a 9, ou seja em ambos os períodos o parâmetro está de acordo com a resolução.

\section{Conclusão}

Neste trabalho foi avaliada a eficiência do sistema de tratamento da ETE-Belém no período de 10 anos (2003 - 2013), ambas apresentaram diferenças no período estudado, cada um com suas particularidades, porém ambos atendem aos padrões de qualidade exigidos pela Resolução CONAMA 430/2011 quanto aos padrões de lançamento.

Para o parâmetro DBO, tanto para o ano de 2003 quanto para o ano de 2013, o descarte do esgoto tratado encontra-se dentro das Resoluções Estadual e Federal atuais.

Para o parâmetro DQO, na falta de regras claras e valores máximos expressos, observa-se que as resoluções são omissas para descarte do esgoto tratado, mas impeditiva para o IQA Paraná, uma vez que o esgoto tratado apresenta valor de $57,50 \mathrm{mg} / 1$ contra o máximo permitido de $50,00 \mathrm{mg} / \mathrm{l}$.

Para os parâmetros sólidos totais e sólidos sedimentáveis, atendem as resoluções vigentes.

Para o parâmetro pH observa-se que a legislação brasileira ainda mantém uma grande amplitude nos valores de descarte do seu efluente 'aceitando' de ácido fraco a básico fraco.

As leis vigentes no Brasil avançaram e muito; o tratamento de esgoto oferecido pela SANEPAR está de acordo com as leis, tanto do MMA, quanto do IAP do estado do Paraná. Acreditamos que a essa situação possa e muito ser melhorada desde que haja uma maior atuação da gestão pública e dos órgãos fiscalizadores, não só local, mas também no âmbito estadual e federal, utilizando-se de medidas de planejamento, de controle, repasse e destinação de verbas e projetos educacionais para a população.

A ETE Belém oferece a população de Curitiba e Região Metropolitana, um despejo no efluente muito satisfatório perante as leis ambientais, devolvendo ao rio uma água que pode sim, ser reaproveitada e usada não só para consumo humano, como também para agricultura, 
pecuária, piscicultura entre outros, porém, ainda não a utiliza para tais fins, não reaproveita a água ou qualquer produto originado, o que, de certa forma, é um desperdício que pode ser contido através de projetos e parcerias com outras empresas que utilizam algum desses produtos que são separados pelo tratamento de esgoto como: água, areia, lodo e biomassa.

Outros estudos como este, poderão verificar a eficiência desses parâmetros, como condições mínimas para a reutilização, se há necessidade de adequar alguns dos parâmetros já existentes, a inclusão de novos parâmetros como vírus, bactérias, outras técnicas de análises, técnicas de tratamento, ou ainda, quais órgãos ou empresas seriam potenciais recicladores do produto, ou dos produtos, resultantes desse tratamento, aproveitando melhor toda a tecnologia empregada para tal, e os objetos dela resultantes.

Porque investir na qualidade do saneamento, tratamento, uso e reuso da água, é algo que não poderá ficar em segundo plano nas ações de planejamento urbano das cidades de todo o mundo, pois a água é um bem tão vital quanto o ar e sol para a vida, e está prestes a entrar em um colapso sem precedentes.

\section{Referências}

ABNT (Associação Brasileira de Normas Técnicas), NBR 9648: Estudo de concepção de sistemas de esgoto sanitário Procedimento. Rio de Janeiro, 1986.

APHA (AMERICAN PUBLIC HEALTH ASSOCIATION). Standard methods for the examination of water and wastewater. $20^{\circ} \mathrm{ed}$. Washington (USA), 1998, 1162p

BASTOS, R.K.X.; BEVILACQUA, P.D.; SILVA, C.A.B.; DORNELAS, F.L. Tratamento de esgotos sanitários e usos múltiplos de efluentes. Revista Brasileira de Engenharia Agrícola e Ambiental, v.9, (Suplemento), p.164-170, 2005. Campina Grande, PB, DEAg/UFCG - www.agriambi. com.br.

BENN, F.R.E; McAULIFFE, C.A. Química e Poluição. Tradução de Luiz Roberto Moraes Pitombo e Sérgio Massaro. Rio de Janeiro: Livros Técnicos e Científicos; São Paulo: Ed. da Universidade de São Paulo, 1981.

BRASIL. Lei $n^{\circ} .11 .445$ de 5 de Janeiro de 2007. Estabelece diretrizes nacionais para o saneamento básico; altera as Leis 6.766, de 19 de dezembro de 1979; 8.036, de 11 de maio de 1990; 8.666, de 21 de junho de 1993; 8.987, de 13 de fevereiro de 1995; revoga a Lei no 6.528, de 11 de maio de 1978; e dá outras providências.

Conselho Nacional do Meio Ambiente - CONAMA. Resolução no 430, de 13 de maio de 2011.
Resolução no 357, de 17 de março de 2005.

CASAN (Companhia Catarinense de Águas e Saneamento). Estação de tratamento de esgoto. s/a. Disponível em: $<$ http.//: www.casan.com.br >Acesso em: 28.abr.2015.

CERON, L.P. Efluentes: resolução CONAMA 430/2011, o que mudou. Revista TAE (on-line); n. 05, Ano I. , 29 fev 2012. Disponível em: http://www.revistatae.com.br/ noticiaInt.asp?id=3704. Acesso em 03 mai 2015.

FERNANDES, C. Digestão anaeróbia. Disponível em: http.//: www.dec.ufcg.edu.br. Acessado em: 27.abr.2015.

FRANCO, P.L.P. análise da potencialidade do reuso indireto potável: estudo de caso da ETE Atuba Sul, região metropolitana de Curitiba. Dissertação de Mestrado da UFPR. Disponível em: http://dspace. c3sl.ufpr.br:8080/dspace/bitstream/handle/1884/24951/ DISSERTACAO\%20PEDRO\%20LUIS\%20PRADO \%20 FRANCO.pdf?sequence=1\&isAllowed=y. Acessado em 25 de mar. 2015.

GRANZIERA, M.L.M. Direito ás águas. Jornal Carta Forense. Ed. 2014. http://cartaforense.com.br/conteudo/ entrevistas/direito-de-aguas/14507. Acesso em 29 abr. 2015.

HENNRICH, I. Inter-relação entre as políticas públicas e o consumo de água não tratada nas comunidades de Santa Rosa e São Pedro no município de Porto União-SC. Dissertação de Mestrado da UnC, 2010. Disponível em: http://www.unc.br/mestrado/editais/DISSERTACAO_DE_ IVAN_HENNRICH.pdf. Acessado em 28 de Mar. 2015.

HESPANHOL, I. O Potencial do Reuso da Água no Brasil: Agricultura, Indústrias e Municípios, Recarga de Aquíferos, Revista Brasileira de Recursos Hídricos, Porto Alegre, v.7, n.4, p. 75 - 95, 2002.

INSTITUTO TRATA BRASIL. Saneamento básico no Brasil. Disponível em: http://www.tratabrasil.org.br/saneamentono-brasil\#PR. Acesso em 22 mar. 2015.

LIBÂNIO, P.A.C.; CHERNICHARO, C.A.L.; NASCIMENTO, N. A dimensão da qualidade da água: avaliação da relação entre indicadores sociais, de responsabilidade hídrica, de saneamento básico e de saúde pública. Engenharia Sanitária e Ambiental, v. 10, n. 3, p. 219-228, 2005.

MELO, J.L.S. et al . Estudo preliminar da remoção de sólidos e turbidez por disposição em solo utilizando efluente pré-tratado por sistemas anaeróbios. XXVII Congresso Interamericano de Engenharia Sanitária e Ambiental, ABES - Associação Brasileira de Engenharia Sanitária e Ambiental. s/a. Disponível em: http://www.bvsde.paho. org/bvsaidis/aresidua/i-103.pdf. Acessado em: 07 ago 2015. 
METCALF, X.X.; EDDY, Y.Y. Wastewater engineering treatment and reuse. 4th ed. Mc GrawHill, 2003.

MINISTÉRIO DAS CIDADES, PlanSab - Plano Nacional de Saneamento Básico. Disponível em: $<$ www.cidades.gov.br/index.php?option=com_content \&view=article\&id=302:plansab\&catid=84\&Itemid=113> Acesso em 20 mai. 2015.

MINISTÉRIO DO MEIO AMBIENTE. Programa Nacional de Capacitações de Gestores. Licenciamento ambiental das estações de tratamento de esgotos e aterros sanitários. 2009. Disponível em: http://www.mma.gov.br/estruturas/ dai_pnc/_publicacao/76_publicacao19042011110356.pdf. Acessado em 02 jun. 2015.

MINISTÉRIO DO MEIO AMBIENTE. Padrões de lançamento para estações de tratamento de esgotos domésticos. Disponível em: http://www. mma.gov.br/port/conama/processos/EFABF603/ ApresEstacoesTratamEsgotosDomesticos.pdf. Acessado em 11 de jun. 2015.

MINISTÉRIO DA SAÚDE, Portaria nº 2.914 de 11 de dezembro de 2011. Disponível em: http://bvsms.saude. gov.br/bvs/saudelegis/gm/2011/prt2914_12_12_2011.html. Acesso em: 07 de jun. de 2015.

NUVOLARI, A. Esgoto sanitário - coleta, transporte, tratamento e reuso agrícola. 2 ed. São Paulo: Bucher, 2011.

OHIRA, T.H. Fronteira de eficiência em serviços de saneamento no estado de São Paulo. Dissertação apresentada à Escola superior de Agricultura Luiz de Queiroz. 109 f. Dissertação (Mestrado em Ciências). Universidade de São Paulo, Piracicaba, 2005.

RIBEIRO, M.A. Crise da água. Revista do IDEC. № 187. Ano 2014. < http://www.idec.org.br/em-acao/revista/bolafora/materia/a-crise-da-agua> Acesso em: 03 mai. 2015.

SAMAE (Serviço Autônomo Municipal de Água e Esgoto do Município de Caxias do Sul). Apostila do operador de estação de tratamento de água e esgoto. s/a. Disponível em: http://www.samaecaxias.com.br/documents/50537/0/ Apostila\%20Operador\%20ETAE.pdf. Acessado em 01 de jun. 2015.

SANEPAR (COMPANHIA DE SANEAMENTO DO PARANÁ). Processo de tratamento de esgoto. 2010. Disponível em: www.sanepar.com.br. Acessado em: 23 de mar. 2015.

SANTOS, H.F.; MANCUSO, P.C.S. A escassez e o reuso de água em âmbito mundial. In: MANCUSO, P.C.S.; SANTOS, H.F. Reuso de água. Universidade de São Paulo, Faculdade de Saúde Pública, Núcleo de Informações em
Saúde Ambiental. Barueri. SP: Manole, 2003.

SCHILLING, G.E.M.; JAYME, R.S.; CARDOSO, V.L. Estudo Comparativo entre os Sistemas Aeróbio e Anaeróbio no Tratamento de Esgoto das ETE's Belém e Padilha Sul no Município de Curitiba-PR. Revista Eletrônica Multidisciplinar FACEAR. Araucária, 2013.

SNIS (SISTEMA NACIONAL DE INFORMAÇÕES SOBRE SANEAMENTO). Diagnóstico dos serviços de água e esgotos - 2013. Disponível em: <www.snis.gov.br $>$. Acesso em: 27 abr. 2015.

SOARES, S.R.A.; BERNARDES, R.S.; NETTO, O.M.C. Relações entre saneamento, saúde pública e meio ambiente: elementos para formulação de um modelo de planejamento em saneamento. Cadernos de saúde pública, v. 18, n. 6, p. 1713-1724, 2002.

SPERLING, M.V. Princípios básicos de tratamento de esgoto. 2 ed. Minas Gerais: UFMG. 1996a.

Introdução à qualidade das águas e ao tratamento de esgoto. 2 ed. Belo Horizonte: Departamento de Engenharia Sanitária e Ambiental. Universidade Federal de Minas Gerais, 1996b, 243 p.

TRENTIN, P.S.; BOSTELMANN, E. Programa interlaboratorial para sólidos totais, dissolvidos e em suspensão em amostras de água. Revista Banas Metrologia. p. 64, 2010. Disponível em: http://banasmetrologia.com.br/ wp-content/uploads/2012/01/Programa-Interlaboratorial. pdf. Acessado em: 02 ago. 2015.

TESTEZLAF, R. Capitulo 5: Métodos de Irrigação na Superfície. In: PRONI-Programa Nacional de Irrigação. (Org.). TEMPO DE IRRIGAR: MANUAL DO IRRIGANTE. SAO PAULO: MATER, 1987, v.1, p. 54-59.

TRENTIN, C.V. Diagnóstico voltado ao planejamento do uso das águas residuárias para irrigação nos cinturões verdes da região metropolitana de Curitiba-PR. Dissertação (Mestrado em Agronomia), Universidade Federal do Paraná. 2005.

WAGNER, R.V.; MOURA, G.L. Saneamento básico: gestão de serviços de esgoto em um município, en Contribuciones a las Ciencias Sociales, Junio 2013, www.eumed.net/rev/ cccss/24/planejamento.html. Acesso em: 20 mar. 2015.

WHO (WORLD HEALTH ORGANIZATION). Water Sanitation and Hygiene. Disponível em: http://www. who.int/water_sanitation_health/facts2004/en/. Acessado em 01 jul 2015. 